\title{
Additive manufacturing of titanium alloy could modify the pathogenic microbial profile: an in vitro study
}

\author{
João PINGUEIRO(a) \\ Adriano PIATTELLI(b) (iD \\ Juliana PAIVA(a) \\ Luciene Cristina de FIGUEIREDO(a) \\ Magda FERES(a) \\ Jamil SHIBLI(a) \\ Bruno BUENO-SILVA(a)
}

Declaration of Interests: The authors certify that they have no commercial or associative interest that represents a conflict of interest in connection with the manuscript.

\section{Corresponding Author:}

Bruno Bueno-Silva

E-mail: Bruno.silva@prof.ung.br

hitps://doi.org/10.1590/1807-3107bor-2019.vol33.0065

Submitted: June 10, 2019

Accepted for publication: June 13, 2019

Last revision: June 17, 2019

\begin{abstract}
Additive manufacturing (AM) is an emerging process for biomaterials and medical devices. Direct Laser Metal Sintering (DLMS) is an AM technique used to fabricate Ti-6Al-4V implant materials with enhanced surface-related properties compared with wrought samples; thus, this technique could influence microbial adsorption and colonization. Therefore, this in vitro study was conducted to evaluate the impact of different implant production processes on microbial adhesion of periodontal pathogens. Titanium discs produced using two different processes-conventional and $\mathrm{AM}$-were divided into three groups: conventional titanium discs with machined surface (G1), AM titanium discs with chemical treatment (G2) and AM titanium discs without chemical treatment (G3). Subgingival biofilm composed of 32 species was formed on the titanium discs, and positioned vertically in 96-well plates, for 7 days. The proportions of microbial complexes and the microbial profiles were analyzed using a DNA-DNA hybridization technique, and data were evaluated using Kruskal-Wallis and Dunnett tests $(\mathrm{p}<0.05)$. Lower proportions of the red complex species were observed in the biofilm formed in G2 compared with that in G1 $(p<0.05)$. Moreover, the proportions of the microbial complexes were similar between G2 and G3 ( $p>0.05)$. Compared with G1, G2 showed reduced levels of Porphyromonas gingvalis, Actinomyces gerencseriae, and Streptococcus intermedius, and increased levels of Parvimonas micra, Actinomyces odontolyticus, and Eikenella corrodens $(\mathrm{p}<0.05)$. The microbial profile of G3 did not differ from G1 and $\mathrm{G} 2$ ( $\mathrm{p}>0.05)$. The results of this in vitro study showed that titanium discs produced via AM could alter the microbial profile of the biofilm formed around them. Further clinical studies should be conducted to confirm these findings.
\end{abstract}

Keywords: Biofilms; Dental Implants; Peri-Implantitis.

\section{Introduction}

Additive manufacturing (AM) is an innovative technique employed in aerospace research as well as in the production of industrial and medical devices. In dentistry, AM is used to produce zirconia restoration and metal supra-structures for removable partial dentures and dental implants. Titanium implants could be produced via a specific AM technique 
called direct metal laser sintering (DMLS), which offers a new venue for the treatment of implant and abutment surfaces. ${ }^{1,2}$ DLMS present some important benefits for the field of oral implantology, primarily because of its capability to build three-dimensional (3D) components from metal (titanium) powders with minimal or no post-processing requirements. ${ }^{2,3}$ DLMS is based on a high-energy focused laser beam, aimed at specific region of a thin layer of metal powder that directly melts in accordance with a sliced 3D computer-aided design model. ${ }^{3}$ Additionally, this process demonstrates high precision and can thus melt extremely thin sections together in a wide range of geometries and surface topographies. ${ }^{4}$

Implant surface topography plays a pivotal role in protein adsorption as well as in the establishment of the dental supra- and subgingival microbiota. Microbial establishment depends on its successive colonization of the oral cavity and dental materials. Each bacterial species appears to facilitate surface colonization for the subsequent species, resulting in the establishment of an anaerobic gram-negative microbiota. Physical and chemical factors are influenced by the process of titanium production and may further affect the attachment of biofilms to hard surfaces. The surface roughness at micrometer level can increase the surface area, thereby increasing bacterial colonization. Moreover, surface roughness provides protection from shear forces and increases the difficulty of employing cleaning methods to treat ailing implants. ${ }^{5}$ Therefore, the aim of the present in vitro study was to evaluate the impact of two different methods for titanium disc production - conventional and DLMS - and to determine their influence on microbial profile using a subgingival multispecies biofilm in vitro model.

\section{Methodology}

\section{Titanium disks and surface topography}

We used titanium alloy discs (5-mm diameter and 3-mm thickness) made of grade- 4 titanium produced by different methods: machined surface (the control group G1) or DLMS (groups G2 and G3) in this study. DLMS titanium discs were made of titanium alloy $\left(\mathrm{Ti}_{6} \mathrm{Al}_{4} \mathrm{~V}\right)$ powders with a particle size of $25-45 \mu \mathrm{m}$.
This powder was used as a basic material in an argon atmosphere and was sintered together layer by layer via an AM process. The laser (Eosynt ${ }^{\circledR} 270$, EOS, Munich, Germany) used an ytterbium equipment system with a spot size of $0.1 \mathrm{~mm}$, a wavelength of $1054 \mathrm{~nm}$, and a continuous power of $200 \mathrm{~W}$ at a scanning rate of $7 \mathrm{~m} / \mathrm{s}$. Following the DMLS process, the titanium discs presented a porous surface covered by certain spherical non-fused titanium particles. To remove these non-fused titanium particles, the discs were sonicated for $5 \mathrm{~min}$ in distilled water at $25^{\circ} \mathrm{C}$ and immersed in $\mathrm{NaOH}(20 \mathrm{~g} / \mathrm{L})$ and hydrogen peroxide $(20 \mathrm{~g} / \mathrm{L})$ at $80^{\circ} \mathrm{C}$ for $30 \mathrm{~min}$. The sonication step was repeated for $5 \mathrm{~min}$ in distilled water. Thereafter, an organic acid treatment was performed in a mixture of $50 \%$ oxalic acid and $50 \%$ maleic acid at $80^{\circ} \mathrm{C}$ for $45 \mathrm{~min}$, followed by washing for $5 \mathrm{~min}$ in distilled water in a sonic bath (G2). Group G3 did not receive the organic acid treatment.

Furthermore, five additional titanium discs from each group were first examined for chemical composition using X-ray photoelectron spectroscopy/ electron spectroscopy for chemical analysis (XPS/ESCA), and no significant pollution was detected. Thereafter, topographies at the microscale were visualized using routine scanning electron microscopy (SEM) control. At the nanoscale, SEM confirmed that both surface types were nano-smooth, according to the current definition.

Atomic force microscopy (AFM, PicoSPM I plus 2100 PicoScan Controller, in contact mode) was used for the surface topography analysis. The AFM scanned $620 \times 420-\mu \mathrm{m}$ areas of each specimen. The measured parameters, such as the arithmetic mean of all profile point absolute values ( $\mathrm{Ra})$, the root-mean-square of all point values $(\mathrm{Rq})$, and the maximum height of the profile (Rt), were recorded for each group. In addition, representative images of the surfaces of each group of specimens were obtained using SEM.

\section{Biofilm formation}

The species used in the subgingival multispecies biofilm in vitro model were Actinomyces naeslundii ATCC 12104, Actinomyces oris ATCC 43146, Actinomyces gerencseriae ATCC 23840, Actinomyces israelii ATCC 12102, Veillonella parvula ATCC 10790, Actinomyces 
odontolyticus ATCC 17929, Streptococcus sanguinis ATCC 10556, Streptococcus oralis ATCC 35037, Streptococcus intermedius ATCC 27335, Streptococcus gordonii ATCC 10558, Streptococcus mitis ATCC 49456, Aggregatibacter actinomycetemcomitans ATCC 29523, Capnocytophaga ochracea ATCC 33596, Capnocytophaga gingivalis ATCC 33624, Eikenella corrodens ATCC 23834, Capnocytophaga sputigena ATCC 33612, Campylobacter showae ATCC 51146, Eubacterium nodatum ATCC 33099, Fusobacterium nucleatum vincentii ATCC 49256, Parvimonas micra ATCC 33270, Fusobacterium nucleatum polymorphum ATCC 10953, Fusobacterium periodonticum ATCC 33693, Prevotella intermedia ATCC 25611, Streptococcus constellatus ATCC 27823, Porphyromonas gingivalis ATCC 33277, Tannerella forsythia ATCC 43037, Streptococcus anginosus ATCC 33397, S. mutans ATCC25175, Selenomonas noxia ATCC 43541, Propionibacterium acnes ATCC 11827, and Gemella morbillorum ATCC $27824 .{ }^{6}$

Most species were cultured on tryptone soy agar plus $5 \%$ sheep's blood under anaerobic conditions (85\% nitrogen, $10 \%$ carbon dioxide, and $5 \%$ hydrogen); $P$. gingivalis was grown on tryptone soy agar plus yeast extract, $1 \%$ hemin, $5 \%$ menadione, and $5 \%$ sheep blood, and T. forsythia was grown on tryptone soy agar plus yeast extract enriched with $1 \%$ hemin, $5 \%$ menadione, $5 \%$ sheep blood, and $1 \% \mathrm{~N}$-acetylmuramic acid. After $24 \mathrm{~h}$ of growth, all species were transferred to cylindrical tubes with brain heart infusion (BHI) culture medium (Becton Dickinson, Sparks, MD) supplemented with $1 \%$ hemin. Bacterial species were allowed to grow for $20 \mathrm{~h}$ and the optical density of the media in the tubes was adjusted to contain approximately $10^{8}$ cells $/ \mathrm{mL}$ of each species. The individual cell suspensions were diluted to obtain a final $15-\mathrm{mL}$ biofilm inoculum with $10^{5}$ cells $/ \mathrm{mL}$. $^{6}$

Round-shaped titanium discs were placed vertically in a 96-well plate to act as substrate for biofilm formation. There were three groups of titanium discs: G1, which were discs with machined surface (control); G2, which were discs produced via AM of titanium with chemical treatment, and G3, which were discs produced via AM of titanium without chemical treatment. A total of $150 \mu \mathrm{L}$ inoculum aliquot containing $10^{4}$ cells of each species was added into each well with a disc and plates were incubated at $37^{\circ} \mathrm{C}$ under anaerobic conditions. After $72 \mathrm{~h}$ of incubation, the culture media was replaced with fresh BHI broth (supplemented with 1\% hemin and 5\% sheep blood) and maintained at $37^{\circ} \mathrm{C}$ under anaerobic conditions until 7 days of biofilm formation.

\section{Checkerboard DNA-DNA hybridization}

Three 7-day biofilm coated pins from each group were transferred to Eppendorf tubes containing $100 \mu \mathrm{L}$ of TE buffer (10 mM Tris-HCl, 1 mM EDTA [pH 7.6]), and $100 \mu \mathrm{L}$ of $0.5 \mathrm{M} \mathrm{NaOH}$ was added to each tube. The tubes containing the pins and final solution were boiled for $10 \mathrm{~min}$, and the solution was neutralized with the addition of $0.8 \mathrm{~mL}$ of $5 \mathrm{M}$ ammonium acetate. Samples were individually analyzed for the presence and levels of the 31 bacterial species using the DNA-DNA hybridization technique. Briefly, upon lysis of the samples, the DNA was placed onto a nylon membrane using a Minislot device (Immunetics, Cambridge, USA) and fixed to the membrane by baking it at $120^{\circ} \mathrm{C}$ for 20 min. The membrane was placed in a Miniblotter 45 (Immunetics). Digoxigenin-labelled whole genomic DNA probes for 31 bacterial species were hybridized in individual lanes of the Miniblotter. Following hybridization, the membranes were washed and DNA probes were detected using a specific antibody to digoxigenin conjugated to phosphatase alkaline. The signals were detected using AttoPhos substrate (Amersham Life Sciences, Arlington Heights, USA), and results were obtained using Typhoon Trio Plus (Molecular Dynamics, Sunnyvale, USA). Two lanes in each membrane contained the standards with $10^{5}$ and $10^{6}$ cells of each species. Signals obtained were converted to absolute counts via comparison with the standards on the same membrane. Failure to detect a signal was recorded as zero. The values obtained from tested groups were compared with the values of negative and positive controls. Counts below the method detection limit $\left(1 \times 10^{4}\right)$ were considered as zero.

\section{Statistical analysis}

Implant surface characterization was analyzed using the analysis of variance (ANOVA) test with 
Bonferroni post hoc tests. Microbiological data using the proportions of complexes (7) and total count of specific bacterial species within biofilms were analyzed using Kruskal-Wallis test, followed by Dunnett post hoc analysis.

\section{Results}

\section{Surface topography}

The groups represented different manufacturing processes and different implant surface topographies. SEM revealed that the G1 group exhibited only the grid of machining (Figure 1A). Conversely, in the G2 and G3 groups, the AM titanium discs exhibited peaks and valleys with diverse irregularities. The G2 group depicted a treated surface and titanium particles fused with the surface (Figure 1B), whereas the G3 group exhibited titanium particles in both weak and hard fused contritions on the surface (Figure 1C).

On characterizing the titanium discs using AFM, differences between the surfaces were revealed. G1 showed only the machining grids with peaks of $1.3 \mu \mathrm{m}$ and some regions that were almost flat. The DLMS titanium discs exhibited irregular surfaces with peaks of approximately $6.5 \mu \mathrm{m}$. Table presents the roughness values measured using AFM.

Figure 2 shows the total counts of bacterial species formed on the surface of the three titanium disc groups. The total counts were $53.4 \times 10^{5}\left( \pm 20.5 \times 10^{5}\right)$ in the G1 group, $62.0 \times 10^{5}\left( \pm 43.7 \times 10^{5}\right)$ in G2, and $50.7 \times 10^{5}\left( \pm 18.7 \times 10^{5}\right)$ in G3 $(\mathrm{p}>0.05)$. There were no significant differences among groups

Figure 3 shows the proportions of each microbial complex formed on the three titanium disc groups. Discs produced using AM with chemical treatment (G2) presented a significantly lower proportion of red complex species (approximately 45\% reduction) compared with machined surface $\operatorname{discs}(\mathrm{G} 1=0.37 \%$ versus $\mathrm{G} 2=0.21 \% ; \mathrm{p}<0.05)$. The comparison between G2 and G3 and between G1 and G3 revealed no statistically significant differences for any complex.

Figure 4 presents the mean counts of each bacterial species. Biofilm formed in G2 presented lower counts of $P$. gingivalis, A. gerencsiae, and S. intermedius and higher counts of P. micra, A. odontolyticus, and E.
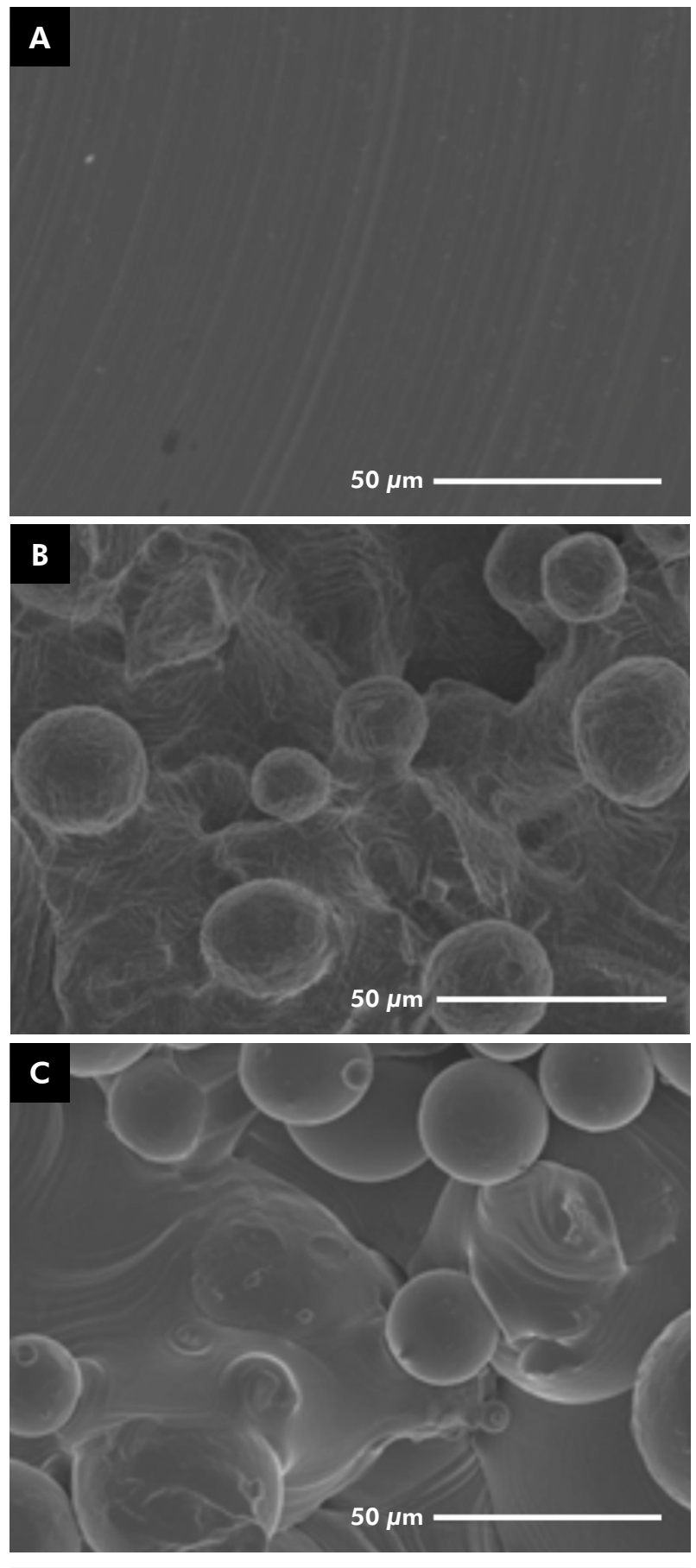

Figure 1. Scanning electronic microscopy of $A: G 1$, discs with machined surface; $B$ : $G 2$, discs produced via the additive manufacturing of titanium with chemical treatment and $C$ : G3, discs produced via the additive manufacturing of titanium without chemical treatment.

corrodens compared with G1 ( $\mathrm{p}<0.05)$. The G3 biofilm microbial profile did not differ from that of $\mathrm{G} 1$ and G2 ( $p>0.05)$. 
Table. Surface roughness $(\mu \mathrm{m})$ of three titanium disc groups: G1, conventional titanium discs with machined surface; G2, AM-produced titanium discs with chemical treatment; and G3, AM-produced titanium discs without chemical treatment.

\begin{tabular}{lccc}
\hline Parameters $(\mu \mathrm{m})$ & $\mathrm{Ra}$ & $\mathrm{Rq}$ & $\mathrm{Rt}$ \\
\hline $\mathrm{G}^{*}$ & 6 & 6.7 & 14.3 \\
$\mathrm{G} 2$ & 23.8 & 27 & 137 \\
$\mathrm{G} 3$ & 14.5 & 18.3 & 106.7 \\
\hline
\end{tabular}

Statistical analysis was performed using ANOVA test with Bonferroni post-test of revealed statistical significance. ${ }^{*} p<0.05$, among values from three groups $(\mathrm{G} 1<\mathrm{G} 2=\mathrm{G} 3)$

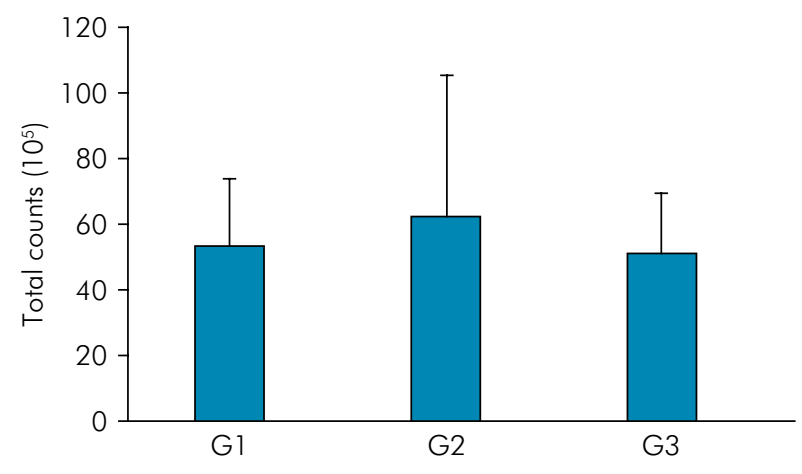

Figure 2. Total bacterial counts $\left(\times 10^{5}\right)$ of biofilms formed on titanium discs surfaces of $G 1$, discs with machined surface; $\mathrm{G} 2$, discs produced via the additive manufacturing of titanium with chemical treatment; and G3, discs produced via the additive manufacturing of titanium without chemical treatment. Results are expressed as means and SDs of three independent experiments in triplicate $(n=9)$. Kruskal-Wallis test revealed no significant differences among groups ( $p>0.05)$.

\section{Discussion}

In this study, biofilms formed on discs produced by additive manufacturing of titanium with chemical treatment showed reduced proportions of red complex species and reduced levels of $P$. gingivalis, a well-known periodontal pathogen. Peri-implantitis is a biofilm-associated disease with an exacerbated inflammatory response that may result in implant loss. ${ }^{8,9}$ Biofilm accumulation with consequent dysbiosis of this biofilm is the primary etiological factor of peri-implantitis. ${ }^{10}$ Periodontitis and peri-implant diseases share some similarities regarding etiological factors and therefore, it has been hypothesized that these two conditions harbor similar periodontal pathogens. The sequence of bacterial colonization appears to be extremely similar between peri-implantitis and periodontitis; moreover, the dysbiotic biofilm appears to be similar between these diseases. ${ }^{9}$ In this regard, the red complex is associated with the etiology of peri-implant diseases, ${ }^{11}$ and $P$. intermedia, an orange complex species, plays a key role in peri-implantitis progress. ${ }^{12}$

Recently, a novel multispecies in vitro biofilm model comprising all microbial complexes previously described ${ }^{7}$ was developed to better mimic the formation of subgingival biofilm. ${ }^{13}$ Reliable in vitro
A

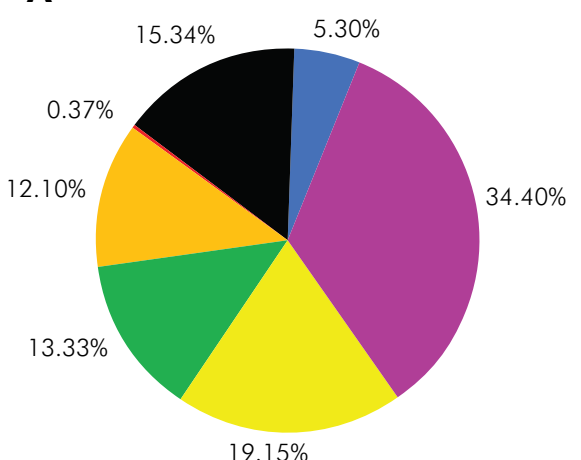

$19.15 \%$
B

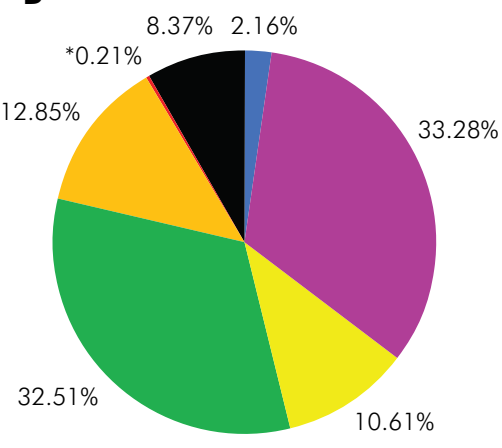

Yellow

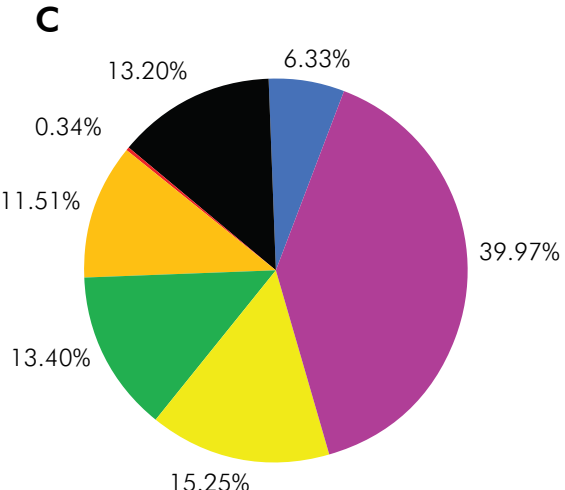

$15.25 \%$

Actinomyces Purple

Figure 3. Mean proportions of the bacterial complexes of biofilms formed on titanium discs surfaces of $G 1$, discs with machined surface; (A) G2, discs produced via the additive manufacturing of titanium with chemical treatment (B); and $G 3$, discs produced via the additive manufacturing of titanium without chemical treatment $(C)$. Three independent experiments in triplicate $(N=9)$ were performed. The colors represent different microbial complexes as described by Socransky et al. (1988). Data were analyzed using the Kruskal-Wallis test, followed by Dunnett post hoc analysis. * indicates significant difference between G1 and G2 (p < 0.05 ). 


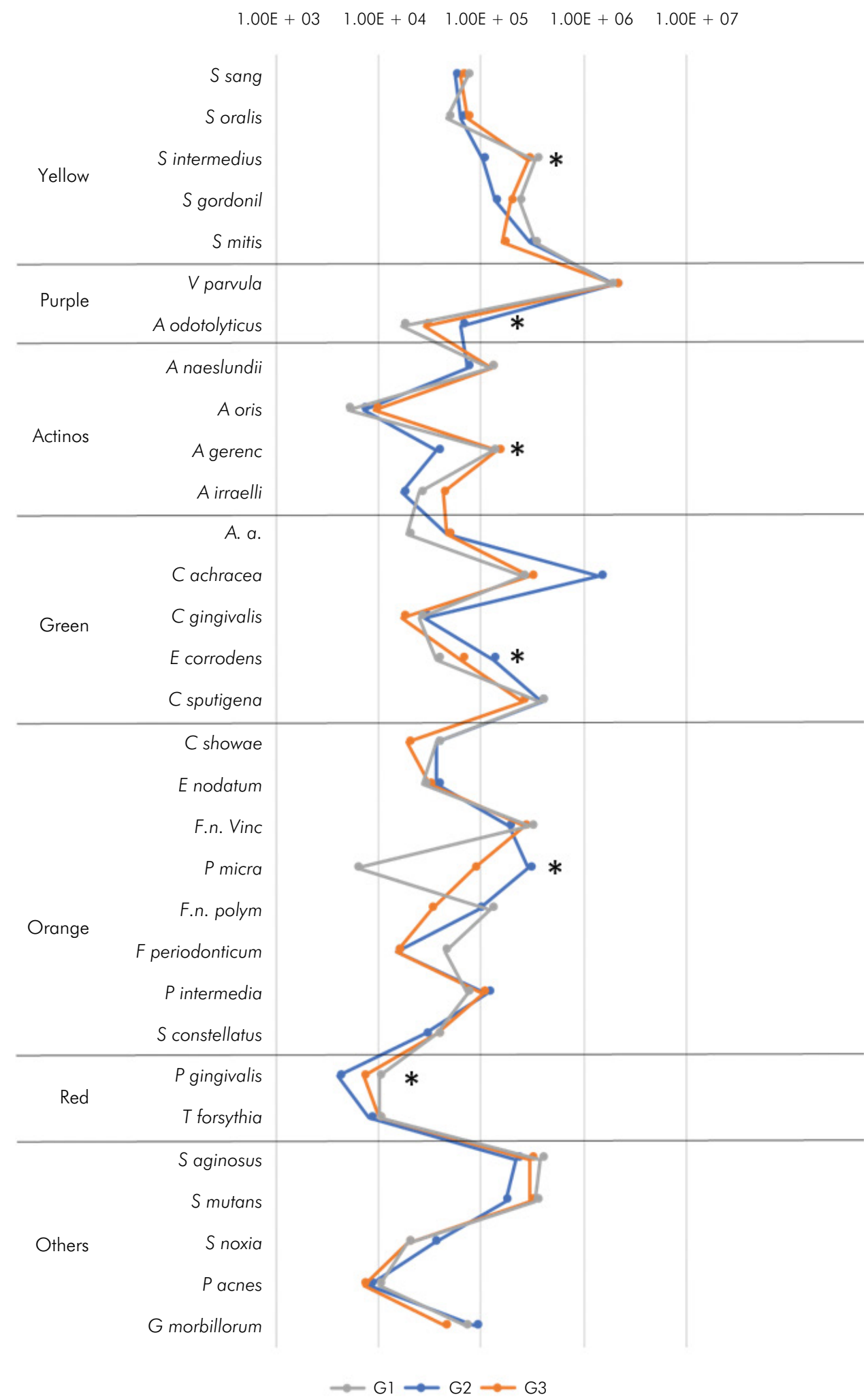

Figure 4. Mean bacterial count (×105) of the bacterial species formed on $G 1$, machined surface discs; G2, discs produced via the additive manufacturing of titanium with chemical treatment; and $G 3$, discs produced via the additive manufacturing of titanium without chemical treatment. Data were analyzed using the Kruskal-Wallis test, followed by Dunnett post hoc analysis.* indicates significant difference between $G 1$ and $G 2$ ( $p<0.05)$. 
reproduction of events occurring in vivo is the key challenge for scientists. In this sense, the present model has an advantage over other biofilm models because it allows the growth of more species. This model could be employed to test therapeutic options ${ }^{6}$ and/or to simulate bacterial adhesion to distinct surfaces, as demonstrated in the current study. Our results are consistent with those of previous studies showing several distinct strategies of surface treatments aiming to reduce bacterial colonization, particularly pathogens colonization. . $^{14,15,16,17}$

A recent systematic review has demonstrated that $P$. gingivalis is the most prevalent pathogen found across peri-implantitis sites..$^{12}$ This bacterium is considered a keystone pathogen responsible for triggering the dysbiosis of subgingival biofilm..$^{10,18}$ Interestingly, biofilms formed on titanium discs produced via AM with chemical treatment in the present study had lower total count of $P$. gingivalis compared with machined surface discs. This feature could be attributed to a different oxide formation over the titanium discs following the chemical treatment for DMLS process. This post-treatment process alters the topography of the implant surface, as observed in our microscopic analysis (Table, Figure 1), and of the oxide layer, which influences bacterial adsorption as previously described ${ }^{19,20}$ In addition, biofilms formed on titanium discs produced via the AM process showed reduced levels of $A$. gerencseriae and S. intermedius, initial colonizers of the biofilm and health-associated species. Although the presence of $S$. intermedius is associated with healthy conditions, elevated counts of this pathogen has been observed in diseased dental implants compared with healthy implants. ${ }^{21}$

On the other hand, we observed elevated counts of P. micra, A. odontolyticus and E. corrodens on titanium discs produced using DMLS with chemical treatment. P. micra is a member of the orange complex, which has been associated with healthy-disease transition. Previous studies have shown that levels of P. micra are reduced following treatment of mucositis and peri-implantitis. ${ }^{22}$ Moreover, $P$. micra is more abundant on dental implants than on natural teeth. ${ }^{23}$ One study has shown that after 18.5 years of follow-up, P. micra, P. gingivalis, P. intermedia, T. forsythia, and Treponema denticola were detected in higher counts surrounding implants than teeth. ${ }^{24}$ E. corrodens, a member of the green complex, was observed in higher counts on mucositis sites compared with healthy implants. ${ }^{25}$

Therefore, the DLMS process associated with chemical treatment modifies the in vitro biofilm profile. Although this process reduced the proportion of red complex and decreased the total counts of $P$. gingivalis, it also favored, albeit to a lesser extent, $P$. micra, which might be related to peri-implant disease. Future in vivo studies should evaluate the efficacy of dental implants produced via AM in reducing the prevalence of peri-implantitis.

\section{Acknowledges}

The DLMS discs were provided by Leader Novaxa, Italy.

\section{References}

1. Mangano C, Mangano FG, Shibli JA, Roth LA, d' Addazio G, Piattelli A, et al. Immunohistochemical evaluation of peri-implant soft tissues around Machined and Direct Metal Laser Sintered (DMLS) Healing Abutments in Humans. Int J Environ Res Public Health. 2018 Jul;15(8):E1611. https://doi.org/10.3390/ijerph15081611

2. Hernández-Nava E, Mahoney P, Smith CJ, Donoghue J, Todd I, Tammas-Williams S. Additive manufacturing titanium components with isotropic or graded properties by hybrid electron beam melting/hot isostatic pressing powder processing. Sci Rep. 2019 Mar;9(1):4070. https://doi.org/10.1038/s41598-019-40722-3

3. Mangano F, Luongo F, Shibli JA, Anil S, Mangano C. Maxillary overdentures supported by four splinted direct metal laser sintering implants: a 3-year prospective clinical study. Int J Dent. 2014;2014:252343. https://doi.org/10.1155/2014/252343

4. Shibli JA, Mangano C, D'avila S, Piattelli A, Pecora GE, Mangano F, et al. Influence of direct laser fabrication implant topography on type IV bone: a histomorphometric study in humans. J Biomed Mater Res A. 2010 May;93(2):607-14.

5. Pita PP, Rodrigues JA, Ota-Tsuzuki C, Miato TF, Zenobio EG, Giro G, et al. Oral streptococci biofilm formation on different implant surface topographies. BioMed Res Int. 2015;2015:159625. https://doi.org/10.1155/2015/159625 
6. Miranda SL, Damasceno JT, Faveri M, Figueiredo L, Silva HD, Alencar SM, et al. Brazilian red propolis reduces orange-complex periodontopathogens growing in multispecies biofilms. Biofouling. 2019 Mar;35(3):308-19. https://doi.org/10.1080/08927014.2019.1598976

7. Socransky SS, Haffajee AD, Dzink JL, Hillman JD. Associations between microbial species in subgingival plaque samples. Oral Microbiol Immunol. 1988 Mar;3(1):1-7. https://doi.org/10.1111/j.1399-302X.1988.tb00596.x

8. Salvi GE, Cosgarea R, Sculean A. Prevalence of Periimplant Diseases. Implant Dent. 2019 Apr;28(2):100-2. https://doi.org/10.1097/ID.0000000000000872

9. Berglundh T, Armitage G, Araujo MG, Avila-Ortiz G, Blanco J, Camargo PM, et al. Peri-implant diseases and conditions: Consensus report of workgroup 4 of the 2017 World Workshop on the Classification of Periodontal and Peri-Implant Diseases and Conditions. J Periodontol. 2018 Jun;89 Suppl 1:S313-8. https://doi.org/10.1002/JPER.17-0739

10. Colombo AP, Tanner AC. The role of bacterial biofilms in dental caries and periodontal and peri-implant diseases: a historical perspective. J Dent Res. 2019 Apr;98(4):373-85. https://doi.org/10.1177/0022034519830686

11. Pérez-Chaparro PJ, Duarte PM, Shibli JA, Montenegro S, Heluy SL, Figueiredo LC, et al. The Current Weight of Evidence of the Microbiologic Profile Associated With Peri-Implantitis: A Systematic Review. J Periodontol. 2016 Nov;87(11):1295-304. https://doi.org/10.1902/jop.2016.160184

12. Lafaurie GI, Sabogal MA, Castillo DM, Rincón MV, Gómez LA, Lesmes YA, et al. Microbiome and microbial biofilm profiles of periimplantitis: a systematic review. J Periodontol. 2017 Oct;88(10):1066-89. https://doi.org/10.1902/jop.2017.170123

13. Soares GM, Teles F, Starr JR, Feres M, Patel M, Martin L, et al. Effects of azithromycin, metronidazole, amoxicillin, and metronidazole plus amoxicillin on an in vitro polymicrobial subgingival biofilm model. Antimicrob Agents Chemother. 2015 May;59(5):2791-8. https://doi.org/10.1128/AAC.04974-14

14. Vilarrasa J, Delgado LM, Galofré M, Àlvarez G, Violant D, Manero JM, et al. In vitro evaluation of a multispecies oral biofilm over antibacterial coated titanium surfaces. J Mater Sci Mater Med. 2018 Nov;29(11):164. https://doi.org/10.1007/s10856-018-6168-8

15. Pantaroto HN, Ricomini-Filho AP, Bertolini MM, Silva JHD, Azevedo Neto NF, Sukotjo C, et al. Antibacterial photocatalytic activity of different crystalline TiO2 phases in oral multispecies biofilm. Dent Mater. 2018;34(7):e182-e95. https://doi.org/10.1016/j.dental.2018.03.011

16. Godoy-Gallardo M, Wang Z, Shen Y, Manero JM, Gil FJ, Rodriguez D, et al. Antibacterial coatings on titanium surfaces: a comparison study between in vitro single-species and multispecies biofilm. ACS Appl Mater Interfaces. 2015 Mar;7(10):5992-6001. https://doi.org/10.1021/acsami.5b00402

17. Ishijima M, de Avila ED, Nakhaei K, Shi W, Lux R, Ogawa T. Ultraviolet Light Treatment of Titanium Suppresses Human Oral Bacterial Attachment and Biofilm Formation: A Short-Term In Vitro Study. Int J Oral Maxillofac Implants. 2019 Feb. https://doi.org/10.11607/jomi.7444

18. Hajishengallis G, Lamont RJ. Beyond the red complex and into more complexity: the polymicrobial synergy and dysbiosis (PSD) model of periodontal disease etiology. Mol Oral Microbiol. 2012 Dec;27(6):409-19. https://doi.org/10.1111/j.2041-1014.2012.00663.x

19. Eick S, Gadzo N, Tacchi M, Sculean A, Potempa J, Stavropoulos A. Gingipains impair attachment of epithelial cell to dental titanium abutment surfaces. J Biomed Mater Res B Appl Biomater. 2019 Feb. https://doi.org/10.1002/jbm.b.34345

20. Shibli JA, Martins MC, Lotufo RF, Marcantonio E Jr. Microbiologic and radiographic analysis of ligature-induced peri-implantitis with different dental implant surfaces. Int J Oral Maxillofac Implants. 2003 May-Jun;18(3):383-90.

21. Persson GR, Renvert S. Cluster of bacteria associated with peri-implantitis. Clin Implant Dent Relat Res. 2014 Dec;16(6):783-93. https://doi.org/10.1111/cid.12052

22. Máximo MB, de Mendonça AC, Renata Santos V, Figueiredo LC, Feres M, Duarte PM. Short-term clinical and microbiological evaluations of peri-implant diseases before and after mechanical anti-infective therapies. Clin Oral Implants Res. 2009 Jan;20(1):99-108. https://doi.org/10.1111/j.1600-0501.2008.01618.x

23. Meyer S, Giannopoulou C, Cancela J, Courvoisier D, Müller F, Mombelli A. Experimental mucositis/gingivitis in persons aged 70 or over: microbiological findings and prediction of clinical outcome. Clin Oral Investig. 2019 Jan. https://doi.org/10.1007/s00784-019-02815-1

24. Dierens M, Vandeweghe S, Kisch J, Persson GR, Cosyn J, De Bruyn H. Long-term follow-up of turned single implants placed in periodontally healthy patients after 16 to 22 years: microbiologic outcome. J Periodontol. 2013 Jul;84(7):880-94. https://doi.org/10.1902/jop.2012.120187

25. Renvert S, Roos-Jansåker AM, Lindahl C, Renvert H, Rutger Persson G. Infection at titanium implants with or without a clinical diagnosis of inflammation. Clin Oral Implants Res. 2007 Aug;18(4):509-16. https://doi.org/10.1111/i.1600-0501.2007.01378.x 